\title{
Aspectos químicos e estruturais da qualidade fisiológica de sementes de soja
}

\author{
Mariney de Menezes(1), Édila Vilela de Resende von Pinho(1), Solange Carvalho Barrios Roveri José(2), \\ Alexana Baldoni( ${ }^{(1)}$ e Flávia Ferreira Mendes ${ }^{(1)}$
}

\begin{abstract}
(1)Universidade Federal de Lavras, Departamento de Fitotecnia, Caixa Postal 3037, CEP 37200-000 Lavras, MG. E-mail: marineym@gmail.com, edila@ufla.br, alexanabaldoni@yahoo.com.br, flvmendes2001@yahoo.com.br (2)Embrapa Recursos Genéticos e Biotecnologia, Parque Estação Biológica, Avenida W5 Norte (final), Caixa Postal 02372, CEP 70770-900 Brasília, DF. E-mail: solangebr@cenargen.embrapa.br
\end{abstract}

Resumo - O objetivo deste trabalho foi avaliar os efeitos gênicos aditivos e não aditivos para as características da espessura das camadas da testa e da lignina presente nessas camadas, e verificar se os caracteres utilizados para avaliação da qualidade fisiológica das sementes de soja se correlacionam com o teor de lignina do tegumento. Foram usadas três cultivares (M-Soy 8400, CD 201, CD 206) de alta e três (CD 215, CD 202, Savana) de baixa qualidade fisiológica, para se obterem sementes híbridas $F_{1}$ e $F_{2}$, inclusive os recíprocos, pelo sistema de cruzamento dialelo parcial e as linhagens parentais. Os parâmetros primeira contagem de germinação, contagem final de germinação e velocidade de germinação, utilizados para avaliação da qualidade fisiológica, podem ser correlacionados com o teor de lignina. Foram observadas correlações positivas entre o teor de lignina e a percentagem de plântulas normais no teste de envelhecimento ao 5 e 11ㅇa dias após a semeadura, com valores maiores de correlação no 5ำ dia. A correlação entre velocidade de germinação e teor de lignina foi negativa. A análise do dialelo apontou significância do efeito recíproco, o que indica que a espessura das camadas da testa e a espessura de lignina nessas camadas podem ser explicadas pelo efeito materno.

Termos para indexação: Glycine max, cruzamento dialélico, lignina, tegumento.

\section{Chemical and structural aspects of the physiological quality of soybean seeds}

\begin{abstract}
The objective of this work was to evaluate the additive and non-additive genetic effects for thickness of the seed coat layers and of the lignin present in them, and to verify if the characters used to evaluate the physiological quality of the seeds is correlated with the lignin content. Three cultivars (M-Soy 8400, CD 201, CD 206) with high and three (CD 215, CD 202, Savana) with low physiological quality were used to obtain $F_{1}$ and $F_{2}$ hybrid seeds, including the reciprocals, using partial diallel crosses and the parental lines. First germination count, final germination count and germination rate, used to evaluate the physiological quality, can be correlated with lignin content. Positive correlations were observed between lignin content and the percentage of normal seedlings in the aging test at the $5^{\text {th }}$ and $11^{\text {th }}$ days after sowing, with the highest correlation values at the $5^{\text {th }}$ day. The correlation between germination rate and lignin content was negative. The diallel analysis showed reciprocal effect, showing that the thickness of the seed coat layers and of the lignin contained in these layers can be explained by maternal effect.
\end{abstract}

Index terms: Glycine max, diallel cross, lignin, seed coat.

\section{Introdução}

A qualidade fisiológica de sementes de soja é em grande parte influenciada pelo genótipo. Nos últimos anos, os programas de melhoramento genético têm buscado desenvolver materiais com características como resistência a doenças e pragas, teores de óleo e proteína $\mathrm{e}$, mais recentemente, teor de lignina no tegumento das sementes (Costa et al., 2001).

Em algumas pesquisas, tem sido observado que o teor de lignina no tegumento pode influenciar a qualidade fisiológica das sementes (Panobianco et al., 1999). Nos programas de melhoramento genético, busca-se a seleção de genótipos com teores de lignina superiores a $5 \%$, por apresentarem maior resistência ao impacto mecânico do que cultivares com testa impermeável (Alvarez et al., 1997). Porém, ainda não está devidamente esclarecida a relação entre o teor de lignina e a qualidade fisiológica das sementes de soja.

O tegumento da semente é proveniente dos integumentos do óvulo, e o integumento externo, 
ou primina, origina a testa, enquanto o integumento interno, ou secundina, origina o tégmen. Em um corte transversal da testa de uma semente de soja, podem ser distinguidas quatro camadas a partir da superfície: cutícula, epiderme (células paliçádicas ou macroesclerídeos), hipoderme (células em ampulheta ou células pilares ou osteoesclerídeos) e células parenquimatosas (Swanson et al., 1985). De acordo com Caviness \& Simpson Junior (1974), a espessura do conjunto das quatro camadas da testa da semente de soja pode variar de 70 a $100 \mu \mathrm{m}$, e pode haver variação entre cultivares. Essa característica é constante dentro de cada cultivar e é controlada geneticamente. Na testa das sementes de soja, está presente a lignina, polímero natural associado à qualidade das sementes (Lewis \& Yamamoto, 1990).

Alvarez et al. (1997) e Panobianco et al. (1999) observaram relação direta entre a resistência das sementes a danos mecânicos e os teores de lignina. Também foi observada grande variabilidade genética para a resistência a dano mecânico (Carbonell \& Krzyzanowski, 1995) e para o teor de lignina (Carbonell \& Krzyzanowski, 1995; Alvarez et al., 1997). A lignificação do tegumento confere resistência mecânica ao tecido e protege a parede celular de infecções por microrganismos (Tavares et al., 1987).

Com o auxílio do microscópio eletrônico de varredura (MEV), é possível avaliar a deposição da lignina nas camadas do tegumento e determinar a relação com a qualidade fisiológica das sementes. Utilizando-se principalmente de elétrons secundários (Alves, 2006), a análise estrutural do tegumento das sementes por meio do MEV destina-se, basicamente, ao exame de superfícies internas e determina se elas estão fraturadas e expostas.

Silva et al. (2008), por meio de eletromicrografias de varredura de cortes transversais da testa das sementes, das cultivares de soja M-Soy 8400 e M-Soy 8411, observaram três camadas de células e seu comportamento quando expostas a cinco períodos de envelhecimento acelerado. Foi constatada redução na espessura das camadas da testa das cultivares avaliadas. Essa redução sugere um colapso das células que compõem essas camadas, o que pode estar relacionado com a redução do potencial germinativo.

O objetivo deste trabalho foi avaliar os efeitos gênicos aditivos e não aditivos para as características espessura das camadas da testa e espessura de lignina presente nessas camadas, além de verificar se os caracteres utilizados para avaliação da qualidade fisiológica das sementes de soja se correlacionam com o teor de lignina do tegumento.

\section{Material e Métodos}

$\mathrm{O}$ trabalho foi realizado nas áreas experimentais dos Departamentos de Agricultura e de Ciências Florestais e nos Laboratórios de Análise de Sementes e de Microscopia Eletrônica, da Universidade Federal de Lavras, de 2005 a 2008.

O material das seis cultivares utilizadas neste trabalho foi produzido na safra 2005/2006 e selecionado a partir de testes de germinação, de testes de vigor e das informações das empresas obtentoras das cultivares, classificadas em cultivares com sementes com alta (M-Soy 8400, CD 201, CD 206) e com baixa (CD 215, CD 202, Savana) qualidade fisiológica.

Os cruzamentos foram efetuados manualmente entre plantas das cultivares dos dois grupos formados. As sementes das plantas parentais e $F_{1}$ foram colhidas manualmente no estádio R8, e as vagens foram secas à sombra até as sementes atingirem teor de água de aproximadamente $12 \%$. Para avaliar as características relacionadas ao tegumento das sementes, a geração $\mathrm{F}_{2}$ foi obtida por autofecundação da $F_{1}$.

Para a avaliação da qualidade fisiológica das sementes, foram realizados os testes de envelhecimento acelerado e de velocidade de germinação das sementes envelhecidas. $\mathrm{O}$ período de envelhecimento das sementes foi de 72 horas à temperatura de $42^{\circ} \mathrm{C}$, em umidade relativa próxima a 100\% (Marcos Filho, 1999). Após o envelhecimento, as sementes foram semeadas em papel Germitest e colocadas no germinador previamente regulado à temperatura constante de $25^{\circ} \mathrm{C}$, segundo as Regras para Análise de Sementes (Brasil, 1992). As avaliações foram realizadas no $5^{\circ}$ e $11^{\circ}$ dias após a semeadura, quando foi registrado o número de plântulas com no mínimo $1 \mathrm{~cm}$ de hipocótilo e duas raízes seminais. A velocidade de germinação foi determinada conjuntamente com o teste de germinação, pela fórmula de Edmond \& Drapala (1958) (Nakagawa, 1999). A partir do 2 dia após a semeadura até a estabilização, foi registrado diariamente o número de plântulas que atingiram o mínimo de $1 \mathrm{~cm}$ de radícula. As análises estatísticas foram realizadas por meio do SISVAR para Windows 
(Ferreira, 2003), e a comparação das médias foi feita pelo teste de Scott-Knott, a 5\% de probabilidade.

Para a extração de lignina, foi utilizada a metodologia de Barber \& Ride (1988), com as modificações de Capeleti et al. (2005). As amostras foram obtidas de tegumentos de soja dos parentais, da geração $F_{2}$ e de recíprocos de 100 sementes, macerados com nitrogênio líquido até a obtenção de um pó fino, de onde foram retirados $30 \mathrm{mg}$. Para a determinação da lignina, foi utilizado resíduo seco insolúvel em metanol, que continha lignina e ácidos fenólicos esterificados da parede celular (Barber \& Ride, 1988). A absorbância dessa solução foi determinada a $280 \mathrm{~nm}$, e os valores foram calculados com base na curva de lignina e expressos em miligramas de lignina por grama de tecido seco (Rodrigues et al., 2005). A análise do teor de lignina foi realizada em delineamento experimental inteiramente casualizado, com quatro repetições, e as médias foram comparadas pelo teste de Scott-Knott, a $5 \%$ de probabilidade.

A estimativa da correlação fenotípica entre o teor de lignina e os parâmetros utilizados para avaliação da qualidade fisiológica das sementes foi determinada entre os caracteres, dois a dois, pela expressão proposta por Falconer \& Mackay (1996).

A visualização das células estruturais da testa, por microscopia eletrônica de varredura, foi realizada em tegumentos de cinco sementes de soja dos parentais, da geração $F_{2}$ e de recíprocos analisados de acordo com a metodologia de Alves (2006). Como padrão, foram realizados cortes transversais na parte central do tegumento, para determinação da espessura das camadas das células paliçádicas e das células em ampulhetas. Foi utilizado o delineamento inteiramente casualizado, com dez repetições, e as médias foram comparadas pelo teste de Scott-Knott, a 5\% de probabilidade.

A espessura de lignina foi determinada por microscopia de luz. As seções transversais do terço médio do tegumento foram obtidas por meio de um micrótomo de mesa. As seções transversais foram coradas com Safra-Blau (mistura de azul de astra $1 \%$ e safranina 0,1\%) (Kraus \& Arduin, 1997). Em cada seção, foram feitas fotomicrografias com aumento de 40x, com auxílio de um fotomicroscópio Olympus BX-60. Em cada foto foram feitas três medidas, pelo programa Sigma Scan, das células epidérmicas e das células paliçádicas que estavam coradas de vermelho. A cor vermelha indica a presença de lignina. O experimento foi conduzido em delineamento experimental inteiramente casualizado, com dez repetições. A comparação das médias foi feita pelo teste de Scott-Knott, a 5\% de probabilidade.

As estimativas da capacidade geral (CGC) e da capacidade específica de combinação (CEC) foram determinadas a partir dos dados obtidos para a espessura das camadas das células paliçádicas, das células em ampulhetas, do conjunto de células paliçádicas e em ampulhetas e da espessura de lignina presente nessas camadas. Com esses dados, os parâmetros genéticos foram estimados segundo o modelo dialélico proposto por Griffing (1956) e adaptado ao dialelo parcial (Cruz \& Regazzi, 1994): $\mathrm{Y}_{\mathrm{ij}}=\mathrm{m}+\mathrm{g}_{\mathrm{i}}+\mathrm{g}_{\mathrm{j}}+\mathrm{s}_{\mathrm{ij}}+\mathrm{r}_{\mathrm{ij}}+\mathrm{e}_{\mathrm{ij}}$, em que $\mathrm{Y}_{\mathrm{ij}}$ é o valor médio da combinação híbrida $(i \neq j)$ ou do genitor $(i=j) ; m$ é a média geral; $g_{i}$ é o efeito da capacidade geral de combinação do i-ésimo genitor do grupo $1 ; \mathrm{g}_{\mathrm{j}}$ é o efeito da capacidade geral de combinação do j-ésimo genitor do grupo $2 ; \mathrm{s}_{\mathrm{ij}}$ é o efeito da capacidade específica de combinação entre os genitores de ordem i e j dos grupos 1 e 2 , respectivamente; $r_{i j}$ é o efeito recíproco que mede as diferenças proporcionais pelo genitor $\mathrm{i}$ ou $\mathrm{j}$, quando utilizado como macho ou fêmea no cruzamento ij; $e_{i j}$ é o erro experimental médio associado à observação de ordem ij.

$\mathrm{O}$ efeito recíproco foi obtido pela fórmula $r_{i j}=\left(Y_{i j}-Y_{j i}\right) / 2$, em que $r_{i j}$ é o efeito recíproco que mede as diferenças proporcionais pelo genitor $i$ ou $j$, quando utilizado como macho ou fêmea no cruzamento ij; $Y_{i j}$ é a média do híbrido $F_{2} i$ ou $j$, quando utilizado como fêmea; $Y_{\mathrm{ji}}$ é a média do híbrido $F_{2} \mathrm{j}$ ou $\mathrm{i}$, quando utilizado como macho.

As análises estatísticas foram realizadas pelo aplicativo computacional Genes (Cruz, 1997), e as médias foram comparadas pelo teste de Scott-Knott, a 5 e $1 \%$ de probabilidade.

\section{Resultados e Discussão}

Os teores de lignina no tegumento das sementes variaram nos híbridos, recíprocos e descendentes, independentemente de os parentais apresentarem valores altos ou baixos de lignina (Tabela 1).

Foram observadas correlações positivas a $5 \%$ de probabilidade entre o teor de lignina e a percentagem de plântulas normais no teste de envelhecimento ao $5^{\circ}(0,415)$ e $11^{\circ}(0,209)$ dias de avaliação após a 
semeadura, com maior correlação no 5o dia. No teste de envelhecimento, as sementes foram expostas à temperatura de $42^{\circ} \mathrm{C}$ e à umidade relativa próxima a $100 \%$. Infere-se que a lignina tenha constituído uma proteção para as sementes e proporcionado menor deterioração. A correlação entre velocidade de germinação e teor de lignina foi negativa, ou seja, quanto maior o teor de lignina, menor o tempo para a germinação. A reparação mais rápida dos sistemas de membranas das sementes menos deterioradas propiciaria uma emergência mais rápida das plântulas.

O conjunto das camadas das células paliçádicas e das células em ampulheta variaram de 52,70 a 108,70 $\mu \mathrm{m}$ (Tabela 1). De acordo com Caviness \& Simpson Junior (1974), a espessura das quatro camadas de células da testa (cutícula, células paliçádicas, hipoderme, parênquima lacunoso) de uma semente de soja varia entre 70 e $110 \mu \mathrm{m}$. Esses autores observaram também diferenças entre cultivares e que, dentro de cada cultivar, essa característica física é constante e controlada geneticamente. Essas estruturas podem ser observadas na Figura 1. No presente trabalho, não foram observadas diferenças ultraestruturais entre as cultivares de alta ou baixa qualidade fisiológica de sementes avaliadas. José et al. (2004a) estudaram linhagens de milho tolerantes e intolerantes a alta temperatura de secagem e observaram, na estrutura do pericarpo das sementes, algumas diferenças que podem influenciar a tolerância de alguns genótipos a altas temperaturas de secagem.

De maneira geral, a espessura de lignina foi maior nas células paliçádicas que nas células em ampulheta (Tabela 1). A espessura de lignina nas camadas de células variou nos híbridos e recíprocos, independentemente da qualidade fisiológica das sementes. Em alguns descendentes de cultivares de alta qualidade como parental feminino, como $\mathrm{C} \times 3$ $(40,09 \mu \mathrm{m}), \mathrm{B} \times 1(40,25 \mu \mathrm{m}), \mathrm{B} \times 3(41,08 \mu \mathrm{m}) \mathrm{e}$ A x $2(41,64 \mu \mathrm{m})$, foi observada maior espessura de lignina nas células paliçádicas. Os cruzamentos com parental feminino de cultivares de baixa qualidade, como os híbridos 2 x A $(34,63 \mu \mathrm{m}), 1$ × B $(34,71 \mu \mathrm{m})$,

Tabela 1. Teores de lignina $(\mathrm{g} \%)$, espessura $(\mu \mathrm{m})$ das camadas de células paliçádicas $(\mathrm{CP})$, de células em ampulheta $(\mathrm{CA})$ e do conjunto de células paliçádicas + ampulheta (CPA) de sementes de soja dos genitores, geração $\mathrm{F}_{2}$ e recíprocos, obtidos em microscopia de varredura, e espessura de lignina $(\mu \mathrm{m})$ nessas camadas, obtida por microscopia de luz ${ }^{(1)}$.

\begin{tabular}{|c|c|c|c|c|c|c|}
\hline \multirow[t]{2}{*}{ Tratamento $^{(2)}$} & \multirow[t]{2}{*}{ Lignina } & \multicolumn{3}{|c|}{ Espessura de camadas de células } & \multicolumn{2}{|c|}{ Espessura de lignina } \\
\hline & & $\mathrm{CP}$ & $\mathrm{CA}$ & CPA & $\mathrm{CP}$ & CA \\
\hline 1 & $0,42 \mathrm{c}$ & $34,90 \mathrm{c}$ & $39,00 \mathrm{e}$ & $74,00 \mathrm{~d}$ & $36,95 \mathrm{c}$ & $18,00 \mathrm{a}$ \\
\hline 2 & $0,36 \mathrm{c}$ & $34,00 \mathrm{~d}$ & $26,10 \mathrm{~g}$ & $59,90 \mathrm{~g}$ & $44,41 \mathrm{e}$ & $27,11 \mathrm{~b}$ \\
\hline 3 & $0,48 b$ & $40,40 \mathrm{a}$ & $27,10 \mathrm{~g}$ & $67,40 \mathrm{e}$ & $37,74 \mathrm{c}$ & $16,06 \mathrm{a}$ \\
\hline $1 \times A$ & $0,46 b$ & $32,60 d$ & $43,30 \mathrm{e}$ & $75,80 \mathrm{~d}$ & $37,90 \mathrm{c}$ & $40,63 d$ \\
\hline $1 \times B$ & $0,47 b$ & $32,90 \mathrm{~d}$ & $31,20 \mathrm{f}$ & $64,30 \mathrm{f}$ & $34,71 \mathrm{~b}$ & $17,56 \mathrm{a}$ \\
\hline $1 \times \mathrm{C}$ & $0,45 \mathrm{c}$ & $36,50 \mathrm{c}$ & $32,30 \mathrm{f}$ & $69,10 \mathrm{e}$ & $39,72 d$ & $36,52 \mathrm{c}$ \\
\hline $2 \times \mathrm{A}$ & - & $31,20 \mathrm{e}$ & $21,20 \mathrm{~h}$ & $52,70 \mathrm{~h}$ & $34,63 b$ & $21,90 \mathrm{a}$ \\
\hline $2 \times B$ & $0,41 \mathrm{c}$ & $36,10 \mathrm{c}$ & $29,30 \mathrm{f}$ & $65,50 \mathrm{f}$ & $39,77 d$ & $25,84 \mathrm{~b}$ \\
\hline $2 \times C$ & $0,42 \mathrm{c}$ & $40,80 \mathrm{a}$ & $28,00 \mathrm{~g}$ & $68,80 \mathrm{e}$ & $46,00 \mathrm{e}$ & $43,13 d$ \\
\hline $3 \times \mathrm{A}$ & $0,38 \mathrm{c}$ & $26,70 f$ & $32,90 \mathrm{f}$ & $59,70 \mathrm{~g}$ & $39,38 \mathrm{~d}$ & $87,33 \mathrm{f}$ \\
\hline $3 \times B$ & $0,50 \mathrm{~b}$ & $35,20 \mathrm{c}$ & $46,30 \mathrm{~d}$ & $81,20 \mathrm{c}$ & $36,40 \mathrm{c}$ & $49,47 \mathrm{e}$ \\
\hline $3 \times \mathrm{C}$ & $0,59 a$ & $29,30 \mathrm{e}$ & $42,20 \mathrm{e}$ & $71,50 \mathrm{~d}$ & $41,15 \mathrm{~d}$ & $33,50 \mathrm{c}$ \\
\hline A & $0,37 \mathrm{c}$ & $41,10 \mathrm{a}$ & $22,70 \mathrm{~h}$ & $63,50 \mathrm{f}$ & $44,54 \mathrm{e}$ & $38,72 \mathrm{~d}$ \\
\hline B & $0,60 \mathrm{a}$ & $37,40 \mathrm{~b}$ & $30,80 \mathrm{f}$ & $68,20 \mathrm{e}$ & $38,64 \mathrm{c}$ & $20,17 \mathrm{a}$ \\
\hline $\mathrm{C}$ & $0,42 \mathrm{c}$ & $37,00 \mathrm{~b}$ & $27,60 \mathrm{~g}$ & $64,60 \mathrm{f}$ & $39,76 \mathrm{~d}$ & $19,12 \mathrm{a}$ \\
\hline $\mathrm{A} \times 1$ & $0,54 \mathrm{a}$ & $36,00 \mathrm{c}$ & $45,30 \mathrm{~d}$ & $81,10 \mathrm{c}$ & $37,69 \mathrm{c}$ & $35,38 \mathrm{c}$ \\
\hline$A \times 2$ & $0,41 \mathrm{c}$ & $33,60 \mathrm{~d}$ & $32,80 \mathrm{f}$ & $66,70 \mathrm{e}$ & $41,64 d$ & $31,61 \mathrm{~b}$ \\
\hline $\mathrm{A} \times 3$ & - & $34,80 \mathrm{c}$ & $50,30 \mathrm{c}$ & $85,10 \mathrm{c}$ & $31,92 \mathrm{a}$ & $38,57 \mathrm{~d}$ \\
\hline $\mathrm{B} \times 1$ & $0,48 \mathrm{~b}$ & $42,80 \mathrm{a}$ & $65,90 \mathrm{a}$ & $108,70 \mathrm{a}$ & $40,25 \mathrm{~d}$ & $46,78 \mathrm{e}$ \\
\hline $\mathrm{B} \times 2$ & $0,38 \mathrm{c}$ & $31,10 \mathrm{e}$ & $40,80 \mathrm{e}$ & $71,80 \mathrm{~d}$ & $37,50 \mathrm{c}$ & $37,92 d$ \\
\hline $\mathrm{B} \times 3$ & $0,52 \mathrm{~b}$ & $41,70 \mathrm{a}$ & $54,40 \mathrm{~b}$ & $96,20 \mathrm{~b}$ & $41,08 \mathrm{~d}$ & $61,69 \mathrm{e}$ \\
\hline $\mathrm{C} \times 1$ & $0,49 b$ & $41,20 \mathrm{a}$ & $32,40 \mathrm{f}$ & $73,30 \mathrm{~d}$ & $36,60 \mathrm{c}$ & $22,79 \mathrm{a}$ \\
\hline $\mathrm{C} \times 2$ & $0,46 b$ & $35,80 \mathrm{c}$ & $32,70 \mathrm{f}$ & $68,60 \mathrm{e}$ & $37,82 \mathrm{c}$ & $33,73 c$ \\
\hline $\mathrm{C} \times 3$ & $0,47 b$ & $38,50 \mathrm{~b}$ & $33,90 \mathrm{f}$ & $72,40 \mathrm{~d}$ & $40,09 \mathrm{~d}$ & $47,43 \mathrm{e}$ \\
\hline
\end{tabular}

${ }^{(1)}$ Médias seguidas de letras iguais não diferem entre si pelo teste de Scott-Knott, a $5 \%$ de probabilidade. ${ }^{(2)}$ Cultivares de soja de alta qualidade fisiológica de sementes (A, M-Soy 8400; B, CD 201; C, CD 206) e de baixa qualidade fisiológica de sementes (1, CD 215; 2, CD 202; 3, Savana). 
3 x B $(36,40 \mu \mathrm{m})$, observou-se menor espessura de lignina nas células paliçádicas.

Apesar de não ser clara a relação entre a espessura das camadas das células da testa com a da camada de lignina, ao se compararem os dados de microscopia de varredura aos de microscopia de luz de alguns descendentes - como C x $3(38,50 \mu \mathrm{m})$ e B x $1(42,80 \mu \mathrm{m})$, com maior espessura das células paliçádicas -, foi observada também maior espessura da lignina nessas camadas (C x 3, 40,09 $\mu \mathrm{m}$; B x 1, 40,25 $\mu \mathrm{m}$ ) (Tabela 1 e Figura 1).

No presente trabalho, não foi possível estabeleceruma relação entre a qualidade fisiológica das sementes de soja e os aspectos anatômicos do tegumento, avaliados por meio de microscopia de varredura. Foi observado que as estruturas celulares têm diferentes posições no tegumento, o que dificulta a sua comparação entre sementes de diferentes genótipos. A padronização de cortes para obtenção das amostras e visualização em pontos fixos facilita a comparação entre os diferentes genótipos de soja.

A espessura das camadas de células paliçádicas apresentou baixos valores de CGC e foi negativa para a cultivar A, classificada como de alta qualidade fisiológica (Tabela 2). Pode-se inferir que um número reduzido de ciclos não é suficiente para selecionar cultivares de soja para essas características. Resultados semelhantes foram observados por José et al. (2004b), ao avaliar linhagens de milho quanto à tolerância a alta temperatura de secagem em diferentes safras.

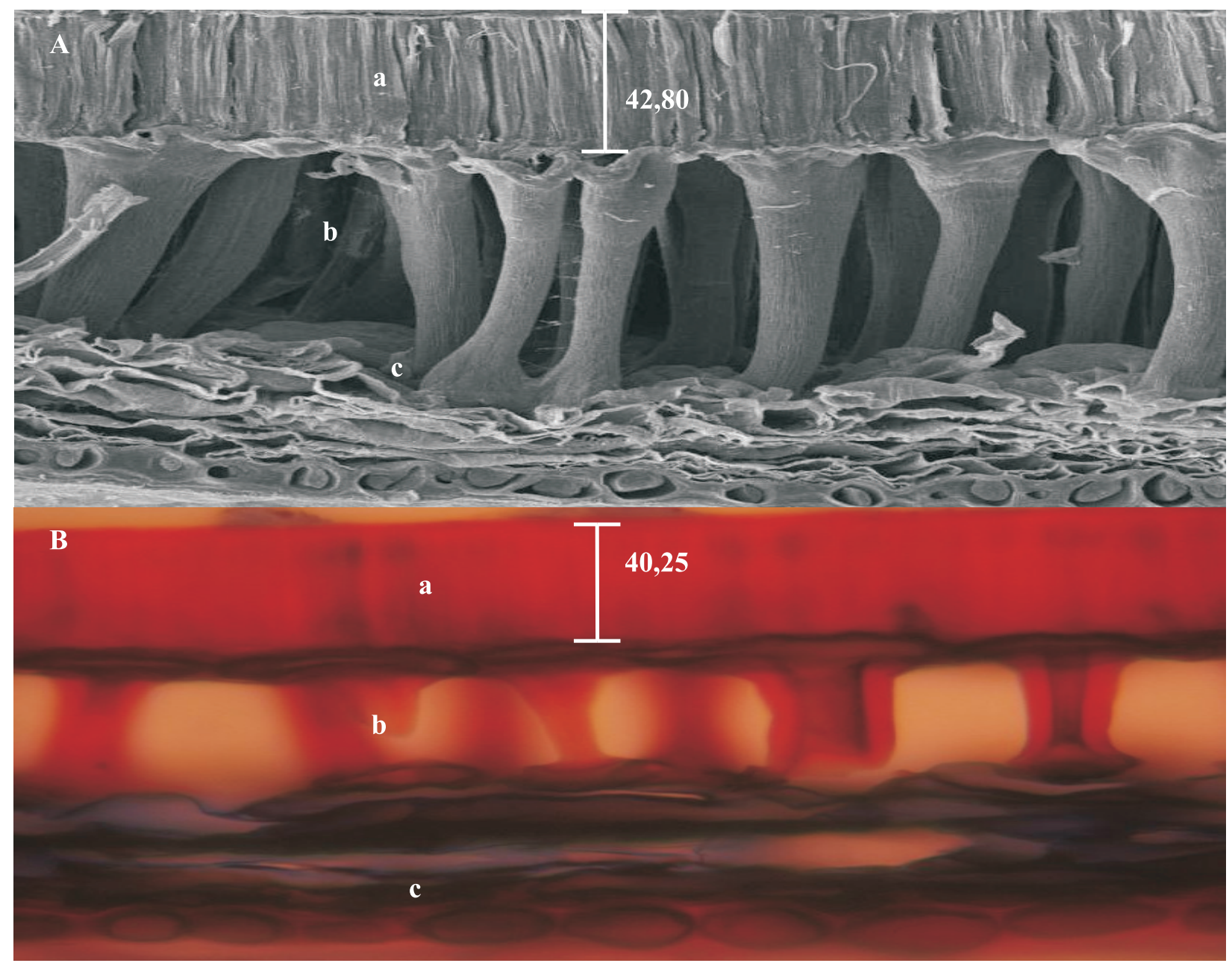

Figura 1. Comparação da espessura $(\mu \mathrm{m})$ das camadas de células paliçádicas $(\mathrm{A})$ de sementes de soja, obtida por microscopia eletrônica de varredura, com a espessura de lignina (B), obtida por microscopia de luz do híbrido B x 1 . a, camada de células paliçádicas; b, camada de células em ampulheta; e c, parênquima lacunoso. 
Altos valores de CEC indicam melhores ou piores combinações, com base na capacidade de combinação dos progenitores. Foram observados maiores valores positivos de CEC para as combinações A x 2 e B x 3 e valores negativos menores para $\mathrm{C} \times 1$. Para a espessura das células em ampulheta, foram observados baixos valores de CGC, com exceção da cultivar B. As combinações $\mathrm{B} \times 1$ e $\mathrm{C} \times 2$ tiveram os maiores valores positivos de $\mathrm{CEC}$, e $\mathrm{C}$ x 3 , os menores valores negativos. A análise das células paliçádicas e em ampulheta em conjunto (Tabela 2) mostrou que os valores de CGC e de CEC foram superiores. CGC manteve-se alta para as cultivares B e 1. Para CEC, foram observados maiores valores para as combinações $\mathrm{B} \times 1$ e $\mathrm{C} \times 2$ e valores negativos menores para $\mathrm{C} \times 3$. A maioria das combinações híbridas foi significativa para o efeito recíproco da espessura das camadas da testa e tornou-se uma característica importante na seleção dos genitores (Tabela 3), o que indica efeito materno ou extracromossômico para a característica em questão. $\mathrm{O}$ efeito materno é utilizado para explicar os resultados recíprocos para a herança dos teores de proteínas nos grãos de soja e feijão, de óleo nos grãos

Tabela 2. Efeitos das capacidades gerais (CGC1 e CGC2) e específicas (CEC) de combinação para espessura das células paliçádicas, em ampulheta e o conjunto delas, em sementes de soja, considerando-se todos os cruzamentos em que foram obtidos híbridos e recíprocos.

\begin{tabular}{|c|c|c|c|c|}
\hline \multirow[t]{2}{*}{ Cultivar $^{(1)}$} & \multicolumn{3}{|c|}{$\mathrm{CEC}$} & \multirow[t]{2}{*}{ CGC1 } \\
\hline & 1 & 2 & 3 & \\
\hline & \multicolumn{4}{|c|}{ Células paliçádicas } \\
\hline A & $-1,52$ & 2,57 & $-1,05$ & $-2,48$ \\
\hline B & 1,54 & $-3,65$ & 2,11 & 1,25 \\
\hline $\mathrm{C}$ & $-0,022$ & 1,08 & $-1,05$ & 1,22 \\
\hline \multirow[t]{2}{*}{ CGC2 } & 2,72 & $-3,78$ & 1,05 & - \\
\hline & \multicolumn{4}{|c|}{ Células em ampulheta } \\
\hline A & $-2,2$ & $-2,27$ & 4,47 & $-0,36$ \\
\hline B & 7,5 & $-5,17$ & $-2,33$ & 10,53 \\
\hline $\mathrm{C}$ & $-5,3$ & 7,43 & $-2,13$ & $-10,17$ \\
\hline \multirow[t]{2}{*}{ CGC2 } & 4,7 & $-7,73$ & 3,03 & - \\
\hline & \multicolumn{4}{|c|}{ Conjunto de células paliçádicas e em ampulheta } \\
\hline A & $-3,8$ & 0,47 & 3,33 & $-2,8$ \\
\hline B & 9,2 & $-9,03$ & 0,17 & 11,8 \\
\hline $\mathrm{C}$ & $-5,4$ & 8,56 & 3,17 & $-9,0$ \\
\hline CGC2 & 7,26 & $-11,4$ & 4,13 & - \\
\hline
\end{tabular}

${ }^{(1)}$ Cultivares de soja de alta qualidade fisiológica de sementes (A, M-Soy 8400; B, CD 201; C, CD 206) e de baixa qualidade fisiológica de sementes (1, CD 215; 2, CD 202; 3, Savana). de soja e de metionina nos grãos de feijão (Pereira et al., 1990).

Estimativas baixas e negativas de CGC para espessura de lignina nas células paliçádicas foram observadas para as cultivares A, C, 1 e 3 (Tabela 4). Os maiores valores de CEC foram observados para sementes oriundas dos cruzamentos A x 2 e $\mathrm{C}$ x 3, e os menores, para a combinação $\mathrm{C} \times 2$. A espessura de lignina teve valores de CGC e CEC maiores nas células em ampulheta que nas células paliçádicas. Foram observados maiores valores da estimativa de CGC para as cultivares $\mathrm{B}$ e 3 . Os maiores valores de CEC foram encontrados nas combinações A x 1 e C x 2, e os menores, na combinação $B \times 2$. Essa mesma tendência foi constatada para a espessura de lignina das células paliçádicas e em ampulheta. Valores elevados de CEC foram encontrados nas combinações A x 1 e A x 2, com o menor valor para $\mathrm{B} \times 2$. A maioria das combinações híbridas foi significativa para o efeito recíproco da espessura de lignina nas células paliçádicas, em ampulheta e no conjunto de células paliçádica e em ampulheta (Tabela 5), o que indica efeito materno ou extracromossômico. O controle desse caráter é uma característica importante para a seleção dos genitores nos programas de melhoramento. Esses programas procuram genótipos com teores de lignina superiores a 5\%, por serem mais resistentes ao impacto mecânico do que cultivares com testa impermeável (Alvarez et al., 1997).

Tabela 3. Efeito recíproco para espessura das células paliçádicas, em ampulheta e o conjunto delas, em sementes de soja, considerando-se todos os cruzamentos em que foram obtidos híbridos e recíprocos.

\begin{tabular}{lccc}
\hline Cultivar $^{(1)}$ & 1 & 2 & 3 \\
\hline \multicolumn{3}{c}{ Células paliçádicas } \\
A & $1,70^{* *}$ & $1,20^{\text {ns }}$ & $4,05^{* *}$ \\
B & $4,95^{* *}$ & $-2,50^{* *}$ & $3,25^{* *}$ \\
C & $-2,35^{* *}$ & $-2,50^{* *}$ & $4,60^{* *}$ \\
\hline \multicolumn{3}{c}{ Células em ampulheta } \\
A & $1,00^{\text {ns }}$ & $5,80^{* *}$ & $8,70^{* *}$ \\
B & $17,35^{* *}$ & $5,75^{* *}$ & $4,05^{* *}$ \\
C & $0,05^{\text {ns }}$ & $2,35^{\text {ns }}$ & $-4,15^{* *}$ \\
\hline \multicolumn{4}{c}{ Conjunto de células paliçádicas e em ampulheta } \\
A & $2,65^{\text {ns }}$ & $7,00^{* *}$ & $12,70^{* *}$ \\
B & $22,20^{* *}$ & $3,15^{\text {ns }}$ & $7,50^{\text {ns }}$ \\
C & $2,10^{\text {ns }}$ & $-0,10^{\text {ns }}$ & $0,45^{\text {ns }}$ \\
\hline
\end{tabular}

${ }^{(1)}$ Cultivares de soja de alta qualidade fisiológica de sementes (A, M-Soy 8400; B, CD 201; C, CD 206) e de baixa qualidade fisiológica

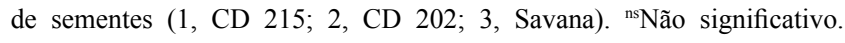
**Significativo a $1 \%$ de probabilidade. 
Tabela 4. Efeitos das capacidades gerais (CGC1 e CGC2) e específicas (CEC) de combinação para espessura de lignina de sementes de soja nas células paliçádicas, em ampulheta e no conjunto delas, considerando-se todos os cruzamentos em que foram obtidos híbridos e recíprocos.

\begin{tabular}{|c|c|c|c|c|}
\hline \multirow[t]{2}{*}{ Cultivar $^{(1)}$} & \multicolumn{3}{|c|}{ CEC } & \multirow[t]{2}{*}{ CGC1 } \\
\hline & 1 & 2 & 3 & \\
\hline & \multicolumn{4}{|c|}{ Células paliçádicas } \\
\hline A & 0,72 & 3,85 & $-4,57$ & $-1,21$ \\
\hline B & 0,75 & $-2,81$ & 2,06 & 1,32 \\
\hline $\mathrm{C}$ & $-1,46$ & $-1,05$ & 2,51 & $-0,12$ \\
\hline \multirow[t]{2}{*}{$\mathrm{CGC} 2$} & $-0,11$ & 0,70 & $-0,59$ & - \\
\hline & \multicolumn{4}{|c|}{ Células em ampulheta } \\
\hline A & 4,75 & 1,55 & $-6,30$ & $-4,36$ \\
\hline B & 2,54 & $-5,75$ & 3,21 & 9,25 \\
\hline $\mathrm{C}$ & $-7,30$ & 4,20 & 3,09 & $-4,89$ \\
\hline \multirow[t]{2}{*}{ CGC2 } & $-4,56$ & $-5,12$ & 9,68 & - \\
\hline & \multicolumn{4}{|c|}{ Conjunto de células paliçádicas e em ampulheta } \\
\hline A & 5,46 & 5,41 & $-10,87$ & $-5,56$ \\
\hline B & 3,29 & $-8,56$ & 5,26 & 10,57 \\
\hline $\mathrm{C}$ & $-8,75$ & 3,15 & 5,61 & $-5,01$ \\
\hline CGC2 & $-4,67$ & $-4,42$ & 9,09 & - \\
\hline
\end{tabular}

${ }^{(1)}$ Cultivares de soja de alta qualidade fisiológica de sementes (A, M-Soy 8400; B, CD 201; C, CD 206) e de baixa qualidade fisiológica de sementes (1, CD 215; 2, CD 202; 3, Savana).

Tabela 5. Efeito recíproco para espessura de lignina de sementes de soja na camada de células paliçádicas, em ampulheta e no conjunto delas, considerando-se todos os cruzamentos em que foram obtidos híbridos e recíprocos.

\begin{tabular}{lccc}
\hline Cultivar $^{(1)}$ & 1 & 2 & 3 \\
\hline \multicolumn{3}{c}{ Células paliçádicas } \\
A & $-0,10^{\mathrm{ns}}$ & $3,50^{* *}$ & $-3,73^{* *}$ \\
$\mathrm{~B}$ & $2,77^{* *}$ & $-1,13^{\mathrm{ns}}$ & $2,34^{* *}$ \\
$\mathrm{C}$ & $-1,56^{\mathrm{ns}}$ & $-4,09^{* *}$ & $-0,53^{\mathrm{ns}}$ \\
\hline \multicolumn{3}{c}{ Células em ampulheta } \\
$\mathrm{A}$ & $-2,62^{\mathrm{ns}}$ & $4,82^{* *}$ & $-24,38^{* *}$ \\
$\mathrm{~B}$ & $14,61^{* *}$ & $6,04^{* *}$ & $6,11^{* *}$ \\
$\mathrm{C}$ & $-6,86^{* *}$ & $-4,70^{* *}$ & $6,96^{* *}$ \\
\hline & Conjunto de células paliçádicas e em ampulhetas \\
$\mathrm{A}$ & $-2,73^{\mathrm{ns}}$ & $8,32^{* *}$ & $-8,42^{* *}$ \\
$\mathrm{~B}$ & $17,38^{* *}$ & $4,90^{* *}$ & $8,45^{* *}$ \\
$\mathrm{C}$ & $8,42^{* *}$ & $-8,79^{* *}$ & $6,43^{* *}$ \\
\hline
\end{tabular}

${ }^{(1)}$ Cultivares de soja de alta qualidade fisiológica de sementes (A, M-Soy 8400; B, CD 201; C, CD 206) e de baixa qualidade fisiológica de sementes (1, CD 215;2, CD 202;3, Savana). " Não significativo. $* *$ Significativo a $1 \%$ de probabilidade.

\section{Conclusões}

1. A primeira contagem, a contagem final e a velocidade de germinação, utilizadas para a avaliação da qualidade fisiológica de sementes de soja, podem ser correlacionadas ao teor de lignina.
2. Efeitos gênicos aditivos e não aditivos influenciam a espessura das camadas da testa e de lignina em sementes de soja.

\section{Agradecimentos}

À Coordenação de Aperfeiçoamento de Pessoal de Nível Superior e à Fundação de Amparo à Pesquisa do Estado de Minas Gerais, pelo apoio financeiro.

\section{Referências}

ALVAREZ, P.J.C.; KRYZANOWSKI, F.C.; MANDARINO, J.M.G.; FRANÇA NETO, J.B. Relationship between soybean seed coat lignin content and resistance to mechanical damage. Seed Science and Technology, v.25, p.209-214, 1997.

ALVES, E. Introdução à microscopia eletrônica de varredura. Lavras: FAEPE, 2006. 43p.

BARBER, M.S.; RIDE, J.P. A quantitative assay for induced lignification in wounded wheat leaves and its use to survey potential elicitors of the response. Physiological and Molecular Plant Pathology, v.32, p.185-197, 1988.

BRASIL. Ministério da Agricultura e Reforma Agrária. Regras para análise de sementes. Brasília: MARA, 1992. 365p.

CAPELETI, I.; FERRARESE, M.L.L.; KRZYZANOWSKI, F.C.; FERRARESE FILHO, O. A new procedure for quantification of lignin in soybean (Glycine max (L.) Merril) seed coat and their relationship with the resistance to mechanical damage. Seed Science and Technology, v.33, p.511-515, 2005.

CARBONELL, S.A.M.; KRZYZANOWSKI, F.C. The pendulum test for screening soybean genotypes for seeds resistant to mechanical damage. Seed Science and Technology, v.23, p.331-339, 1995.

CAVINESS, C.E.; SIMPSON JUNIOR,A.M. Influence of variety and location on seed coat thickness of mature soybean seed. Proceedings of the Associations of Seed Analysis, v.64, p.102-108, 1974.

COSTA, N.P. da; MESQUITA, C. de M.; MAURINA, A.C.; FRANÇA NETO, J. de B.; PEREIRA, J.E.; BORDINGNON, J.R.; KRZYZANOWSKI, F.C.; HENNING, A.A. Efeito da colheita mecânica da soja nas características físicas, fisiológicas e químicas das sementes em três estados do Brasil. Revista Brasileira de Sementes, v.23, p.140-145, 2001.

CRUZ, C.D. Programa GENES: aplicativo computacional em genética e estatística. Viçosa: UFV, 1997. 442p.

CRUZ, C.D.; REGAZZI, A.J. Modelos biométricos aplicados ao melhoramento genético. Viçosa: UFV, 1994. 390p.

FALCONER, D.S.; MACKAY, T.F.C. Introduction to quantitative genetics. $4^{\text {th }}$ ed. Malaysia: Longman, 1996. 464p.

FERREIRA, D.F. Sisvar. Versão 4.2. Lavras: Ufla, 2003.

GRIFFING, B. Concept of general and specific combining ability in relation to diallel crossing systems. Australian Journal of Biological Science, v.9, p.462-493, 1956. 
JOSÉ, S.C.B.R.; PINHO, É.V. de R. von; PINHO, R.G. von; RAMALHO, M.A.P.; SILVA FILHO, J.L. da. Controle genético da tolerância à alta temperatura de secagem em sementes de milho. Revista Brasileira de Milho e Sorgo, v.3, p.414-428, 2004a.

JOSÉ, S.C.B.R.; PINHO, É.V. de R. von; PINHO, R.G. von; SILVEIRA, C.M. Tolerância de sementes de linhagens de milho à alta temperatura de secagem. Ciência e Agrotecnologia, v.28, p.1107-1114, 2004b.

KRAUS, J.E.; ARDUIN, M. Manual básico de métodos em morfologia vegetal. Seropédica: EDUR, 1997. 198p.

LEWIS, N.G.; YAMAMOTO, E. Lignin: occurrence, biogenesis and biodegradation. Annual Review of Plant Physiology and Plant Molecular Biology, v.41, p.455-496, 1990.

MARCOS FILHO, J. Teste de envelhecimento acelerado. In: KRYZANOWSKI, F.C.; VIEIRA, R.D.; FRANÇA NETO, J. de B. (Ed.).Vigor de sementes: conceitos e testes. Londrina: ABRATES, 1999. cap.3, p.1-24.

NAKAGAWA, J. Testes de vigor baseados no desempenho de plântulas. In: KRYZANOWSKI, F.C.; VIEIRA, R.D.; FRANÇA NETO, J. de B. (Ed.). Vigor de sementes: conceitos e testes. Londrina: ABRATES, 1999. p.2.1-2.21.

PANOBIANCO, M.; VIEIRA, R.D.; KRZYZANOWSKI, F.C.; FRANÇA NETO, J.B. Electrical conductivity of soybean seed and correlation with seed coat lignin content. Seed Science and Technology, v.27, p.945-949, 1999.

PEREIRA, I.A.M.; RAMALHO, M.A.P.; SANTOS, J.B. Efeito materno na determinação do tamanho da semente do feijoeiro (Phaseolus vulgaris L.). Ciência e Prática, v.14, p.283-290, 1990.

RODRIGUES, F.A.; JURICK, W.M.; DATNOFF, L.E.; JONES, J.B.; ROLLINS, J.A. Silicon influences cytological and molecular events in compatible and incompatible rice-Magnaporthe grisea interactions. Physiological and Molecular Plant Pathology, v.66, p.144-159, 2005.

SILVA, M.A.D. da; VIEIRA, R.D.; SANTOS, J.M. dos. Influência do envelhecimento acelerado na anatomia da testa de sementes de soja, cv. Monsoy 8400. Revista Brasileira de Sementes, v.30, p.91-99, 2008.

SWANSON, B.G.; HUGHES, J.S.; RASMUSSEN, H.P. Seed microstructure: review of water inhibition in legumes. Food Microstructure, v.4, p.115-124, 1985.

TAVARES, D.Q.; MIRANDA, M.A.C. de; UMINO, C.Y.; DIAS, G.M. Características estruturais do tegumento de sementes permeáveis e impermeáveis de linhagens de soja, Glycine max (L.) Merrill. Revista Brasileira de Botânica, v.10, p.147-153, 1987.

Recebido em 19 de outubro de 2009 e aprovado em 22 de novembro de 2009 